\title{
Installation of a Dome Shelter on Mount Logan Yukon Territory
}

\section{G. HOLDSWORTH}

\section{INTRODUCTION}

Research activity on the plateau area of Mt. Logan (Keeler, 1969; Holdsworth, 1975, 1977; Houston, 1976) places certain demands on the living conditions of those involved in the research. Generally the living conditions must be of a higher standard than that tolerated by expeditions of a recreational nature operating in the same area. Both the high altitude and the severe weather conditions that can occur require that secure, semi-permanent, well provisioned and relatively spacious shelters must be available for accommodating researchers.

Most conventional tents are generally not robust enough to withstand the intense storms that frequently occur above $5200 \mathrm{~m}(17,000 \mathrm{ft})$. The well known Scott Polar tent and several larger framed structures such as the "Parcoll" (equivalent to the U.S. Jamesway) and the "Versadome" are suitable for temporary (summer) use on the plateau snow surfaces. These latter two structures have been used by the Arctic Institute of North America at a site $650 \mathrm{~m}$ east of the NW Col (Fig. 1). These shelters must be dismantled at the end of each field season and stored. In addition, a lumber and plywood structure is built each summer at the same location in connection with the High Altitude Physiology Program (Houston, 1976). It is not dismantled, but the following spring this building is usually deeply buried in snow drift. It is used as a storage facility for the ensuing summer before it is crushed by further burial. For the glaciological program carried out by the Department of the Environment (Holdsworth, 1977), a more permanent, drift free enclosure was required. A rock outcrop above the NW Col afforded a suitable site for erecting a permanent structure.

\section{Description of site}

In 1976 a hut site was found on a solid rock step on the north side of the NW Col $5360 \mathrm{~m}$ although some excavation was found to be necessary. This was done by blasting in 1977 by J. Wyss and party, who also completed the foundations, constructed the wooden platform and erected the hut.

The site is very exposed, but free of snow drift by virtue of the presence of high winds - expected on occasion to exceed $160 \mathrm{Kmph}(100 \mathrm{mph})$. Both the structure and the platform were secured by $3 / 16$ " wire cable attached to rock bolts fixed into the solid granodioritic rock. Temperatures in the summer (July) are typically -7 to $-10^{\circ} \mathrm{C}$ during the day and $-15^{\circ}$ to $-20^{\circ} \mathrm{C}$ during the night. The mean annual temperature from measurements in ice core holes is close to $-29^{\circ} \mathrm{C}$. Evidence for the existence of high winds is the presence of 


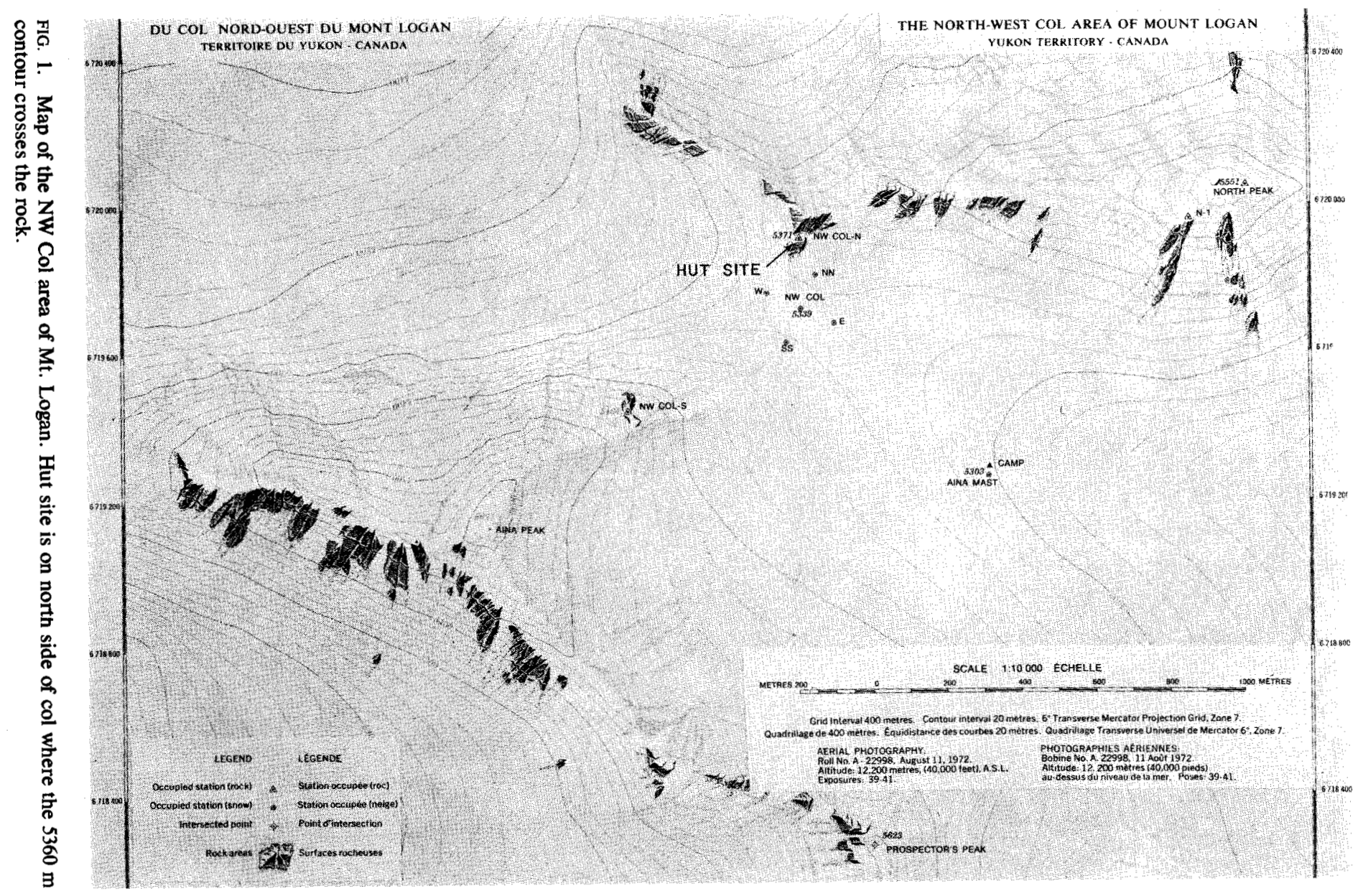


sastrugi, wind blown pebbles on the col, broken accumulation poles and the recording of the damage to two tents at the $5500 \mathrm{~m}(18,000 \mathrm{ft}$.) level in previous years, when in one case, wind speeds were measured at the Arctic Institute camp at $5300 \mathrm{~m}$ level to be $96-112 \mathrm{Kmph}(60-70 \mathrm{mph})$. Wind speeds at this site are generally lower by $30-50 \%$ than the value at the $\mathrm{NW}$ Col and above.

\section{Selection and description of structure}

For minimum wind resistance a circular dome design was selected. Because of the restriction of sites, a base diameter of about $11 \mathrm{ft}(3.35 \mathrm{~m})$ could not be exceeded. A type of geodesic dome (TRI-O-DOME*) manufactured by Triodetic* Building Products Ltd., of Ottawa was selected for the frame. Since neither the standard $10 \mathrm{ft}(3.05 \mathrm{~m})$ nor the $16 \mathrm{ft}(4.88 \mathrm{~m})$ domes were suitable, a hybrid dome was specially made with a base diameter of $10 \mathrm{ft}$ $43 / 4$ " $(3.17 \mathrm{~m})$, a maximum diameter of $11 \mathrm{ft}-6$ " $(3.51 \mathrm{~m})$ and a height of $8 \mathrm{ft}$ $31 / 2$ " $(2.53 \mathrm{~m})$. (Fig. 2). The structure is composed of 138 aluminum tube sections with lengths ranging from about $2-3 \mathrm{ft}(0.6-1 \mathrm{~m})$. The tubes are 1" $(2.54 \mathrm{~cm})$ diameter, 0.065 " $(1.7 \mathrm{~mm})$ wall thickness, 6061 Aluminum with crimped ends possessing grooves and ridges running at a specified angle to the length of the tube. To form the structure, the ends of the tubes are inserted edgewise into a matching key-way on an annular hub which forms the node or junction of up to six tubes. The tubes are held in place by a nutted stove bolt with capturing washers at either end, except at four equally spaced nodes in the fourth ring where ring bolts were used so that anchoring guy lines could be attached.

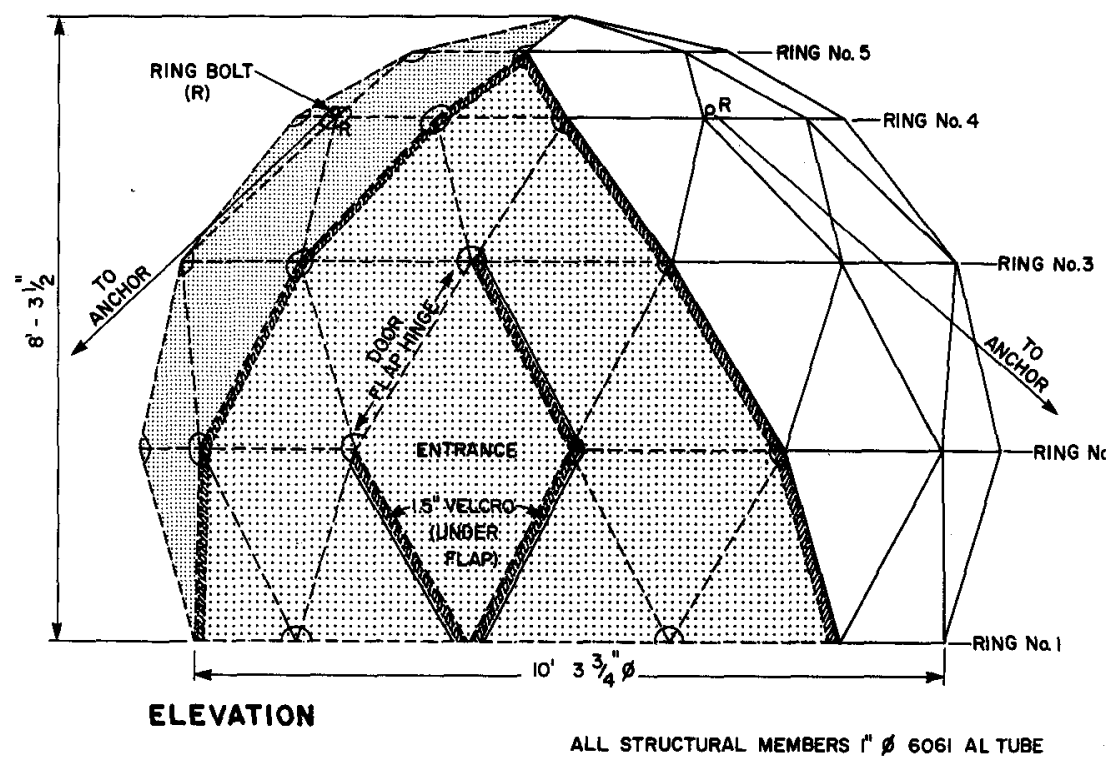

FIG. 2. Plan and elevation of the dome showing cut-away view of main canopy. Outer neoprene nylon canopy is not shown. For details see text. Frame detail courtesy of Triodetic* Building Products Ltd., Ottawa. 
The canopy

A specially designed external canopy was manufactured by Ottawa Awning and Canvas Ltd. It consists of $16 \mathrm{oz}$ neoprene nylon covering the section around the two entrances $(\mathrm{ABC}$ in Fig. 2 and the diametrically opposite section). These sections are sewn to heavy duty ripstop nylon which covers the remainder of the dome. A zippered vent (Fig. 2b) occupies a quadrilateral element above the fourth ring. There is also a zippered gauze flap on the inside. The ripstop nylon sections are heavily reinforced at nodal points to prevent wear in the material. Velcro tape is sewn along the junctions between the neoprene nylon surrounding the entrances and the ripstop nylon, on top of which is an outer cover of neoprene nylon identical to the material covering the frame around the two entrances. There are four reinforced slits in the outer cover to allow the ring bolts to pass through and a zippered flap over the vent element. The outer cover can be firmly closed along the velcro strips or rolled up to the level of the fourth ring exposing the corresponding amount of ripstop nylon. These options, as with the use of the vent, are exercised depending on the particular weather conditions existing at the time. An interior frost liner made from light weight cotton canvas was made but not installed because of the usefulness of the exposed tubing for hanging items, especially clothing. Nevertheless, condensation of body moisure on the inside

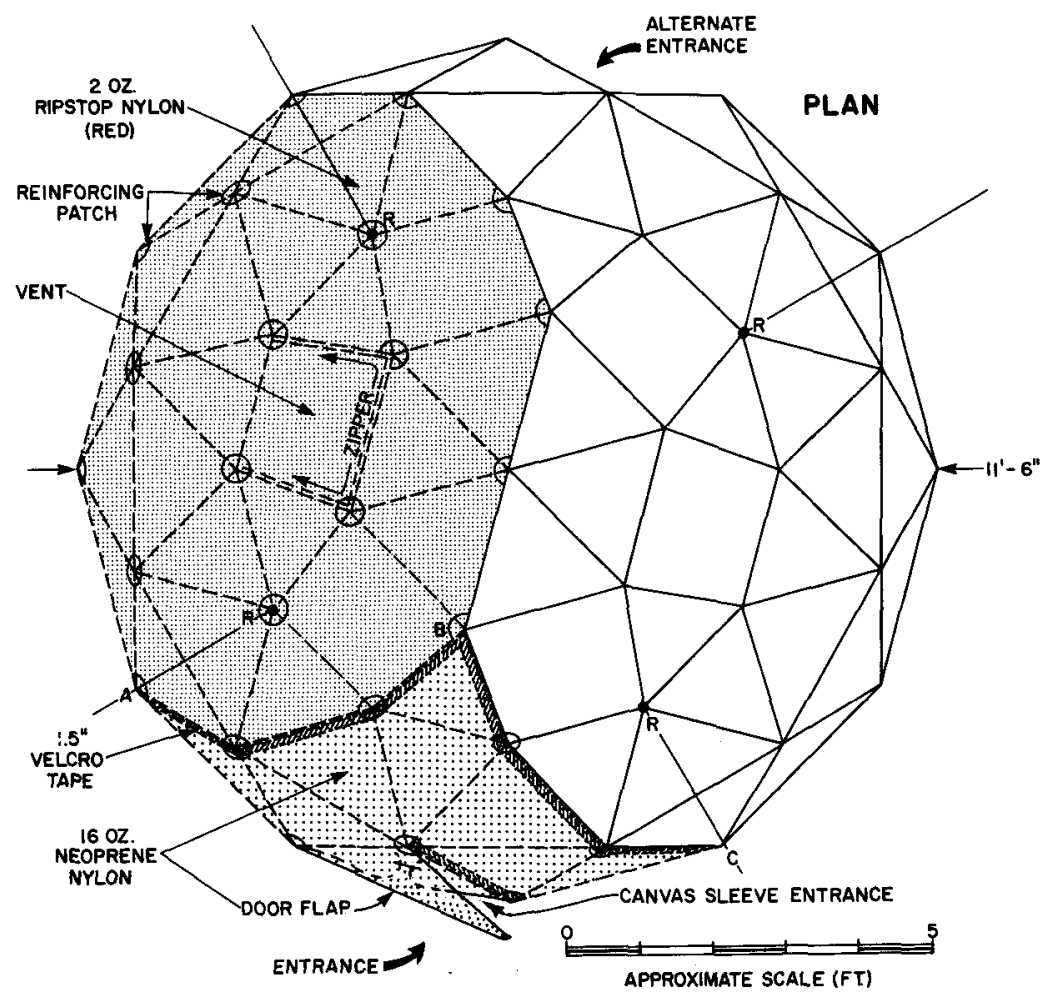


of the dome and the subsequent dripping was an inconvenience (reduced by the use of sponges) and it is highly recommended that a frost liner be used. Whenever possible, the outer neoprene nylon cover should be rolled up and the vent open to facilitate moisure transfer. The black outer surface and silver inner surface of the neoprene nylon was selected for maximum heat absorption and retention. This resulted in a warm interior during the day. Because the neoprene-nylon is not "breathable", the outer cover was rolled back to expose the permeable ripstop nylon. In conjunction with the vent this provided sufficient air flow and light, necessary if cooking is to be done inside the dome. The sleeve entrances are made from canvas and have cord ties to close them. The outer flap of neoprene nylon is fastened down by means of a velcro strip along two sides of the quadrilateral entrance element.

The foundations and installation of the structure

A $10 \mathrm{ft}-6$ " (3.2 m) square wooden platform was built from nailed 2" $\mathrm{x} 4$ "' lumber and 1" $x$ 6" tongue and groove planking. The platform rests on firm or excavated rock. Wire cable, $3 / 16$ " in diameter, secures the platform to solid rock by means of rockbolts inserted into the bedrock. The TRIODOME* frame was assembled on the platform from the bottom ring to the apex in a logical manner (Fig. 3). After the main canopy was installed, foam rubber strips were inserted between the bottom ring and the platform to prevent snow drift from entering under the dome. Interior extensions or flaps of the canopy were laid

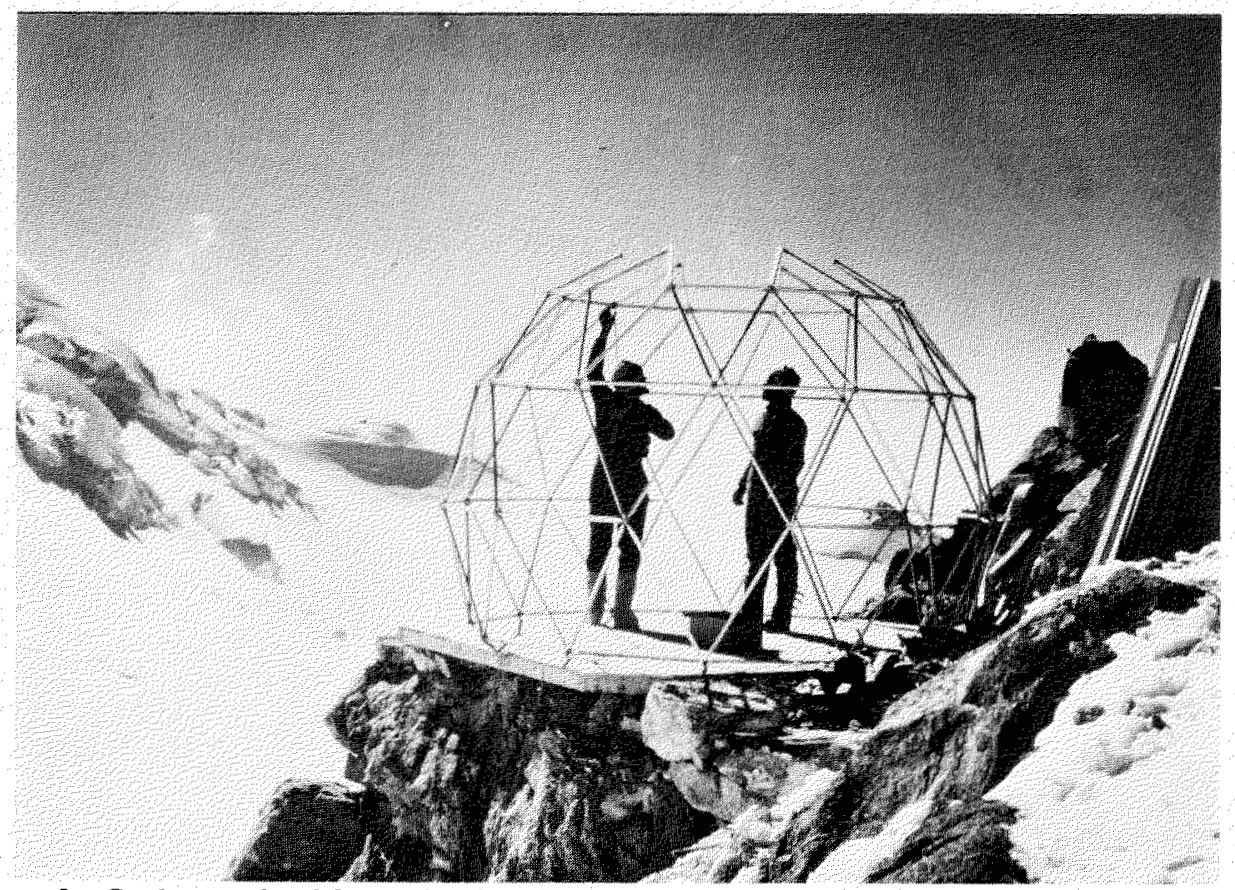

FIG. 3. Partly completed frame showing elemental structure. The NW Col is to the left. (Photo by J. Wyss). 


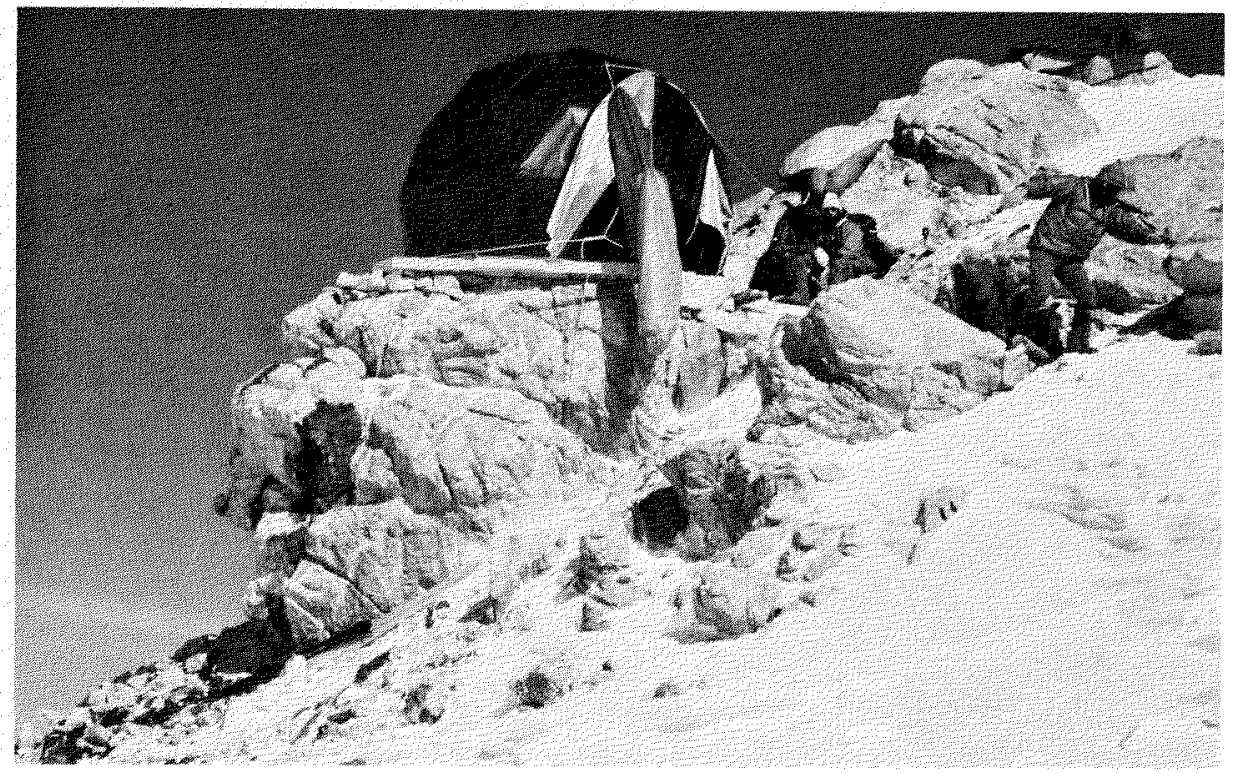

FIG. 4. Completed hut showing part of outer canopy pealed back over inner nylon cover. (G. Holdsworth).

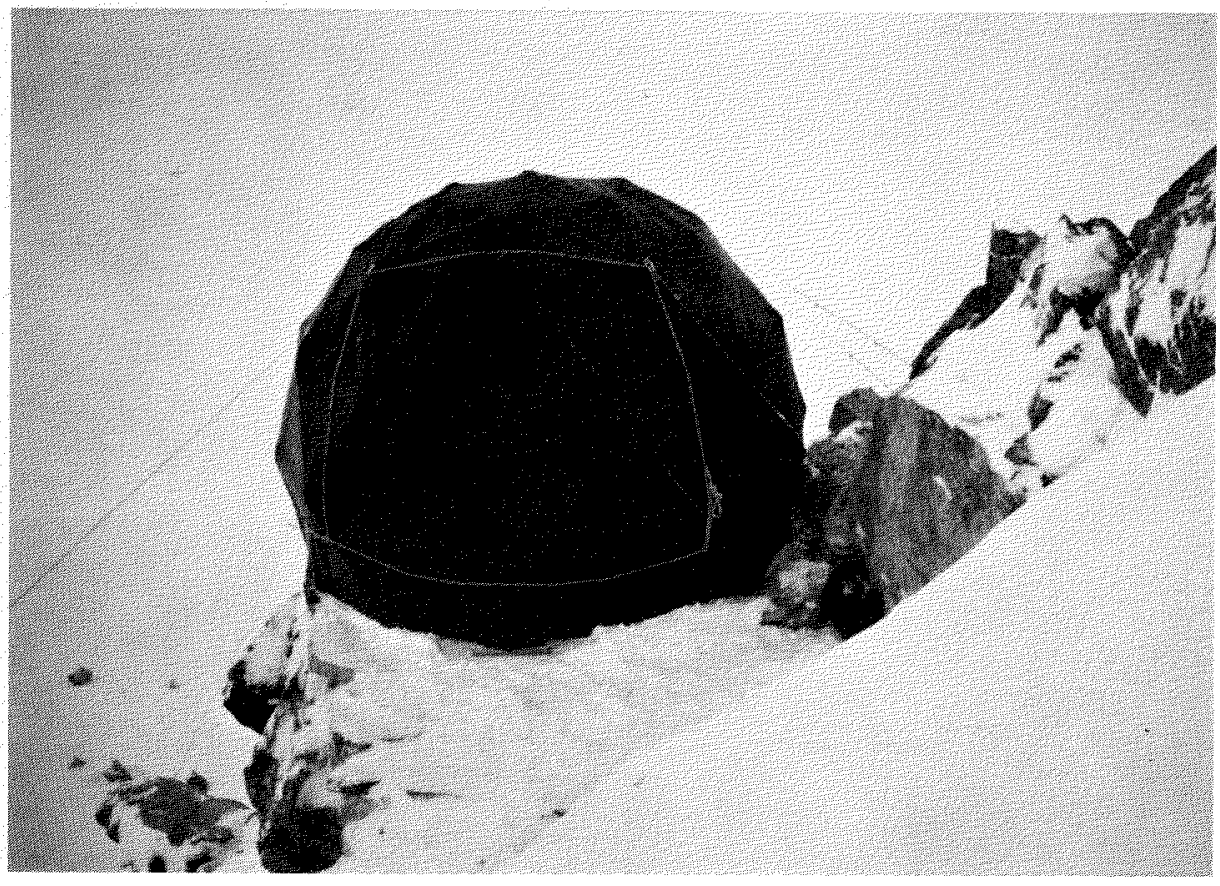

FIG. 5. Hut prepared for winter. (Photo by J. Wyss). 
out and a woven fibre nylon tarpaulin was inserted underneath. Staples were then shot through both materials into the floor. The lower ring of the frame was then fixed in place by attaching conduit clamps which were screwed into the floor through the flaps. This sealed the floor. Upon the fitting of the outer canopy, the guy lines were connected to the ring bolts and tightened against the anchors with turnbuckles. This completes the essential steps in the installation of the hut. Figure 4 shows the completed hut.

Before leaving the site the construction party tied $11 \mathrm{~mm}$ polypropylene rope around the dome, across the Velcro joins and nailed wooden cleats into the platform against the outer edge of the lower ring where the outer canopy fits over it. The hut was left in this condition over the 1977-78 winter (Fig. 5). In July, 1978, the hut was found to be in excellent condition, and was subsequently occupied for three weeks by five persons.

\section{Observations relating to enclosure design and performance}

Upon entering the hut a small quantity of ice was found on the west side encasing parts of the pipe. It was evidently derived from snow which had worked up through the space between the bottom of the outer canopy and the ripstop nylon. Subsequent thawing temperatures due to absorption of heat by the black canopy had melted the snow which had flowed through the ripstop nylon and had frozen when the temperature had dropped again. Two of the turnbuckles had fallen open, evidently due to continual vibrations of the guy lines during high winds. This had resulted in some wear on the outer canopy as the wire rope clamp must have rubbed against it. Several other minor holes in the canopy may have been due to the impact of rocks driven through the air by high winds. These openings are the other sources of entry for snow lodging between the inner and outer canopies. In no cases were holes found in the outer and the inner canopies in the same spot. However, in some places, the ripstop nylon was worn through where it touched the tubes. All these holes were patched. Rubber cement was used as an adhesive for the neoprene patches.

During cold nights with little wind, significant condensation of body moisure would occur, especially in the upper parts of the dome. This could be alleviated by leaving the vent open (or leaving the gauze cover on) and rolling up a substantial part of the outer canopy (on the down wind side), as well as keeping one of the entrances partly open. Otherwise, as the dome absorbed solar radiation and the interior heated up, water droplets would form, causing a continual drip onto the occupants. Frequent sponging was one solution but a frost liner would be more satisfactory. The TRI-O-DOME* (TRIODETIC* and TRI-O-DOME* are registered trade marks of Triodetic Structures Ltd.) offers comfortable space for four average sized persons. A partial view of the interior is shown in Figure 6.

When more space is desirable, and where the site permits it, a $16 \mathrm{ft}(4.88$ m) diameter, hemispherical TRI-O-DOME may be used. This would be a 12 division design rather than the 16 divisions (sections in the base ring) of the "standard" recreational TRI-O-DOME. The canopy design may be similar to the one used on the smaller dome. 


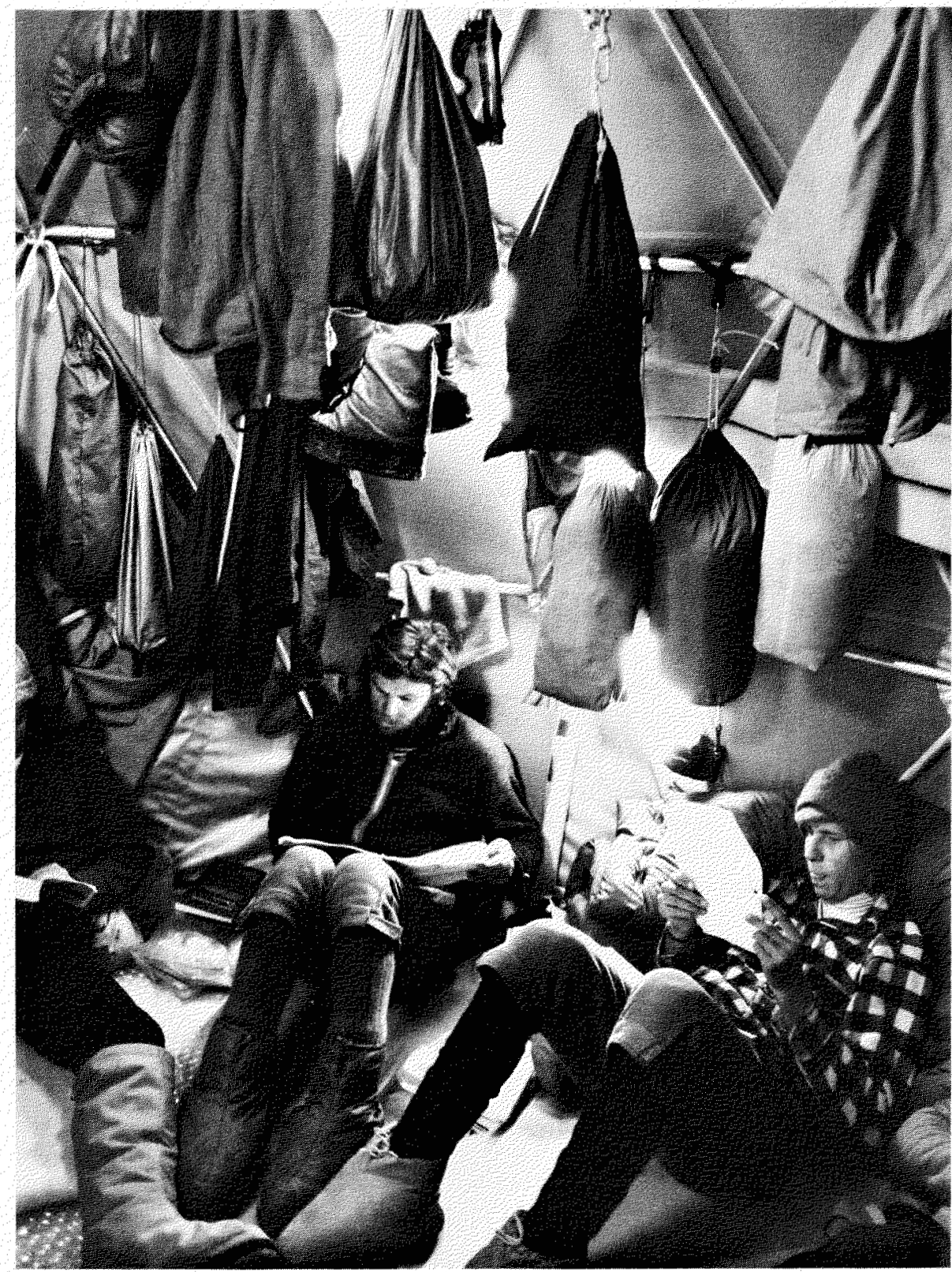

FIG. 6. Part of the interior of the hut showing efficient space utilization. (Photo by G. Holdsworth).

\section{Costs}

In 1977 , prices were $\$ 550$ for the modified $10 \mathrm{ft}$ TRI-O-DOME* and $\$ 600$ for the 12 division, $16 \mathrm{ft}$ TRI-O-DOME*. Galvanized steel tubing is about $20 \%$ cheaper, but it is, of course, heavier. The $16 \mathrm{ft}$ Aluminum frame weighs about $110 \mathrm{lb}(50 \mathrm{Kg})$ and the modified $10 \mathrm{ft}$ dome, somewhat less. 
The canopies cost $\$ 1200$ for the smaller dome and $\$ 1500$ for the $16 \mathrm{ft}$ dome. Although expensive they should give many years of service in a harsh climate. For purely summer use and where reliable winter storage is available, much less expensive canopies may be fabricated. These may be internal to the frame, so that they can be readily detached from it, collapsed and stored. For the $16 \mathrm{ft}$ dome, the weight of the main canopy is about $50 \mathrm{lb}(23 \mathrm{Kg})$ and the outer cover $30 \mathrm{lb}(14 \mathrm{Kg})$. Corresponding values for the smaller dome would be less.

Extra costs are assumed for the platform materials, guy lines, anchors and accessories.

\section{ACKNOWLEDGEMENTS}

I thank Mr. H. G. Fentiman of Triodetic* Building Products Ltd. (Ottawa) for his co-operation in redesigning the smaller dome and for his interest in this enterprise. $\mathrm{Mr}$. R. Cole of Ottawa Awning and Canvas Ltd., undertook the difficult task of fabricating the canopies. Mr. J. Wyss and party erected the entire structure in the field with great care which contributed to the overall stability of the hut. The Arctic Institute of North America provided logistic support in the field.

\section{REFERENCES}

HOLDSWORTH, G. 1975. Taking the measure of Mount Logan. Canadian Geographical Journal, March 1975: 28-33.

HOLDSWORTH, G. 1977. Glaciological Studies on Mt. Logan. Canadian Alpine Journal, 60: 56-58. HOUSTON, C. S. 1976. The Arctic Institute High Altitude Physiology Study, American Alpine Journal, 20(2): 416-428.

KEELER, C. M. 1969. Snow accumulation on Mt. Logan, Yukon Territory, Canada. Water Resources Research, 5(3): 719-723. 